\title{
Is fiscal policy in the euro area Ricardian?
}

\author{
Nikki Panjer ${ }^{1} \cdot$ Leo de Haan $^{2}$ - Jan P. A. M. Jacobs ${ }^{1,3,4}$ (D) \\ Published online: 17 January 2019 \\ (c) The Author(s) 2019
}

\begin{abstract}
We empirically determine whether a Ricardian or a non-Ricardian regime is more plausible for the euro area, following the research strategy of Canzoneri et al. (Am Econ Rev 91:1221-1238, 2001). A Vector AutoRegressive model for the primary government balance and the government debt is estimated for the period 1980q2-2013q4. Our model uses dummy interaction terms to account for the breaks due to the introduction of the Euro Convergence Criteria (ECC) and the start of the global financial crisis, respectively. No evidence is found in favour of either regime for the pre-ECC period. In the post-ECC period, a Ricardian regime is more plausible. Some evidence points in the direction of a non-Ricardian regime for the period after the start of the financial crisis.
\end{abstract}

Keywords Fiscal policy $\cdot$ Euro area $\cdot$ Ricardian regime

JEL Classification E63 $\cdot$ H62 $\cdot$ H63

\section{Introduction}

According to Woodford (1995), under a 'Ricardian regime' government balances (i.e. government revenues minus expenditures) are determined in such a way that the government budget constraint automatically holds for any price level. In this case,

\footnotetext{
Views expressed are those of the authors and do not necessarily reflect official positions of De Nederlandsche Bank. The authors are grateful for comments from an anonymous referee, Dennis Bonam, Lammertjan Dam, Jakob de Haan, Richard Jong-A-Pin, Alessandro Missale, and seminar participants at the University of Groningen and De Nederlandsche Bank, the SOM Ph.D. Conference (Groningen, 2017), the 8th RCEA Macro-Money-Finance Workshop (Rimini) and the 10th Beyond Basic Questions Workshop (Milan).

Jan P. A. M. Jacobs

j.p.a.m.jacobs@rug.nl

1 Faculty of Economics and Business, University of Groningen, P.O. Box 800, 9700 AV Groningen, The Netherlands

2 De Nederlandsche Bank, Amsterdam, The Netherlands

3 CAMA, Canberra, Australia

4 Cirano, Montréal, Canada
} 
the price level is determined by monetary policy in the same way as traditional monetarist theories describe. However, under a 'non-Ricardian regime' government balances can follow an arbitrary process and the price level adjusts in order to satisfy government solvency. In this case, the equilibrium price level is determined as the unique value that equates the real value of the government debt to the expected present value of future government balances.

Determining the plausibility of Ricardian versus non-Ricardian regimes is particularly important for the euro area as it reveals the ability of the European Central Bank (ECB) to achieve price stability by means of monetary policy. According to the Fiscal Theory of the Price Level (hereafter FTPL), evidence in favour of a non-Ricardian regime means that national fiscal policies drive national price levels (Woodford 1994, 1995; Leeper 1991; Sims 1994). Under such circumstances, monetary policy plays a minor role in the determination of prices. Since fiscal policy decisions differ within the euro area, as becomes clear from Fig. 1, the existence of a non-Ricardian fiscal regime will lead to price differences amongst euro area countries. Therefore, if fiscal price determination holds, fiscal policy has to play a larger role in achieving a stable aggregate price level.

Fiscal policy has to play an even greater role in achieving the price stability objective if monetary policy authorities are facing a zero lower bound, as is the case in the euro area since the Global Financial Crisis (hereafter: GFC). For example, Sims (2016) argues that if the FTPL holds, for expansionary monetary policy to be effective during periods of low inflation or deflation, fiscal authorities need to use their interest savings (due to the low interest rate) for fiscal expansions. In line with Barro's (1979) Ricardian equivalence theorem, Sims (2016) further argues that for such a fiscal expansion to be effective in increasing aggregate demand and inflation, consumers have to know that the resulting primary government deficits are to be financed by future inflation, not future taxes or spending cuts. In other words, according to the FTPL fiscal and monetary expansions can only be effective at the zero lower bound if combined with a non-Ricardian fiscal regime. Hence,

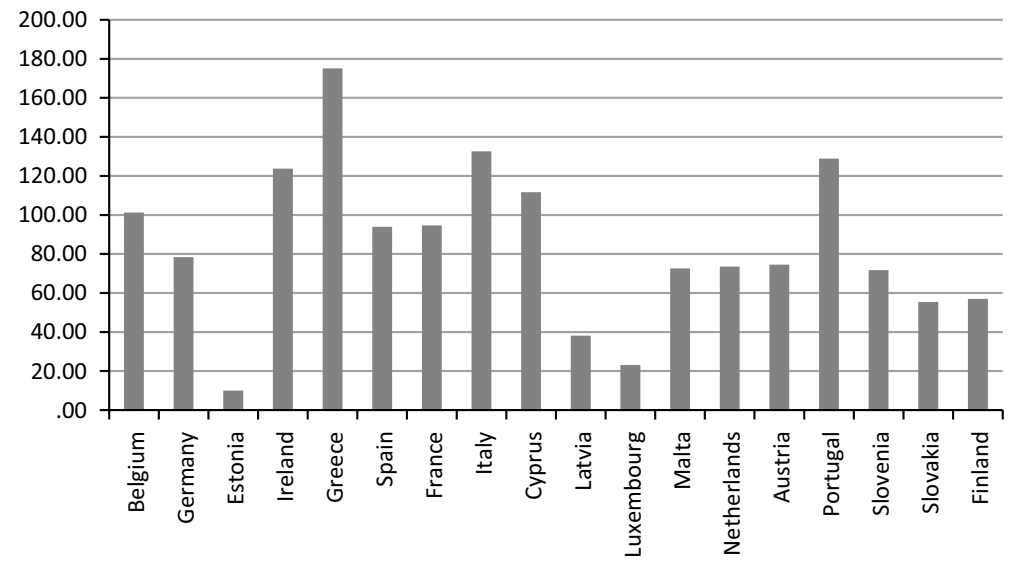

Fig. 1 Debt-to-GDP ratios euro area - 18 countries in $2013 q 4$ 
determining the plausibility of Ricardian versus non-Ricardian regimes in the euro area is particularly relevant as it has implications for the effectiveness of monetary policy in achieving price stability at the current zero lower bound.

Even though euro area members are required to comply with the Euro Convergence Criteria (hereafter: ECC) in order to ensure fiscal discipline, this does not necessarily imply a Ricardian regime. Two important requirements of the ECC are that government deficits and debts are not allowed to exceed $3 \%$ and $60 \%$ of GDP, respectively. These rules are of an asymmetric nature as they only provide upper bounds for deficit and debt ratios. For a Ricardian regime to be in place, government balances need to respond to government debt levels, also in case the ECC rules are not binding. A feedback mechanism between government balances and debt is required to ensure a Ricardian regime (Bohn 1998). Furthermore, since the start of the GFC, government deficits and debt levels have risen sharply. As a consequence, several countries have failed to comply with the $3 \%$ and $60 \%$ boundaries (Schuknecht et al. 2011).

In this paper, we empirically examine whether fiscal policy in the euro area follows a Ricardian or a non-Ricardian regime. We apply the methodology of Canzoneri et al. (2001), who find a Ricardian regime is more plausible for post-war U.S. fiscal data. Specifically, we estimate a bivariate Vector Autoregressive (VAR) model including the primary government balance and government debt, both proportional to GDP. Some studies, like Greiner et al. (2007) and Semmler and Zhang (2004), have applied this methodology to individual euro area countries, but this paper analyses the fiscal regime for the euro area as a whole. Examining fiscal regimes at the aggregated level enables us to discuss implications for the euro area price level and possible frictions between monetary policy and the fiscal regime. We extend the methodology used by Canzoneri et al. by including two dummy interaction terms in our VAR model. Verified by statistical break-point tests, the first dummy interaction term accounts for the implementation of the ECC fiscal requirements around $1997 \mathrm{q} 3$ and the second accounts for start of the GFC around 2008q3. As a result of the inclusion of the two dummy interaction terms, changes in the fiscal regime can be analysed over time.

After having estimated our VAR model, an (unexpected) shock to the government balance is imposed and the plausibility of Ricardian and non-Ricardian regimes is evaluated by means of impulse response functions. Due to the inclusion of the dummy interaction terms, three periods can be distinguished. The first period covers the years before the introduction of the ECC, the second is the period between the introduction of the ECC and the start of the GFC, which more or less overlaps with the great moderation, and the third covers the post-GFC period. Impulse response functions are analysed for these three periods.

The paper proceeds as follows. Section 2 reviews the relevant empirical literature. Section 3 discusses the data. Section 4 presents the methodology that we use to examine the plausibility of Ricardian versus non-Ricardian regimes. Section 5 reports the results. Section 6 concludes. 


\section{Literature}

The existence of non-Ricardian regimes has been proven difficult to test empirically. At first sight, one might wish to estimate a regression equation such as:

$$
P_{t}=\alpha_{1} s_{t}+\alpha_{2} w_{t}+\rho^{\prime} \boldsymbol{X}_{t}+\epsilon_{t},
$$

where $P_{t}$ is the price level in period $t, s_{t}$ is the ratio of the primary government balance to nominal GDP in period $t, w_{t}$ is the ratio of government debt to nominal GDP at the beginning of period $t, \boldsymbol{X}_{t}$ is a vector consisting of a set of other possible determinants of the price level, and $\varepsilon_{t}$ is an error term. Estimates of $\alpha_{1}$ and $\alpha_{2}$ will tell how much the price level depends on the measures of fiscal policy, i.e. $s_{t}$ and $w_{t}$. In a non-Ricardian regime, a negative estimate for $\alpha_{1}$ is expected since a higher government balance induces a lower price level. Unfortunately, finding this negative estimate does not provide convincing evidence for or against a non-Ricardian fiscal regime as a negative relationship between the balance and the price level may exist even in a Ricardian regime. In this case, the causality will run the other way. In a Ricardian regime, if monetary policy induces an increase in the price level, this lowers the real value of outstanding government debt. Taking into account the government budget constraint, balances can be lower. Therefore, a negative relationship exists between the price level and the balance in both a Ricardian and a nonRicardian regime.

Hence, to determine whether fiscal policy is able to determine the equilibrium price level, one needs to focus on fiscal behaviour. Investigating whether balances are set in a way that guarantees government solvency may provide evidence in favour of a Ricardian or a non-Ricardian regime. Many papers attempt to estimate the present value government budget constraint directly, but this approach is heavily criticized by Bohn (1995) as it needs strong assumptions on future discount factors. Instead, Bohn (1998) presents another approach that estimates a fiscal policy rule such as:

$$
s_{t}=\alpha w_{t}+\rho^{\prime} X_{t}+\epsilon_{t},
$$

where $s_{t}$ and $\mathrm{w}_{t}$, are defined as above, and $\boldsymbol{X}_{t}$ is a vector consisting of a set of control variables. Bohn (2005) demonstrates that a positive $\alpha$ is sufficient to satisfy the present value government budget constraint. He finds empirical evidence suggesting that the budget balance responds positively to the beginning-of-period debt in the U.S. during the period 1948-1989. Consequently, the author concludes that U.S. government debt is sustainable for his sample. Bohn's approach has been applied widely. Greiner et al. (2007) estimate a fiscal policy rule for four euro area countries and find evidence in favour of debt sustainability in all cases. This result has often been interpreted as empirical evidence in favour of a Ricardian regime: balances respond to the initial debt level in order for the government to be solvent.

Canzoneri et al. (2001; hereafter CCD) choose a short-run dynamic approach. They analyse the responses of balances and debt after an (unexpected) shock to the balance, thereby determining how both variables are interrelated. Specifically, CCD test whether a Ricardian or a non-Ricardian regime is present in the post-war period for the U.S. by estimating a Vector AutoRegression (VAR) model. Their model 
includes two variables: primary government balances and government liabilities, both proportional to nominal GDP. Government liabilities are defined as government debt plus the monetary base. CCD present the responses of both variables after a shock to the balance. Impulse response functions show that the debt ratio decreases for several periods after a positive shock to the balance. Ricardian regimes provide an intuitive interpretation of this: if government balances unexpectedly increase, debt is paid off. A non-Ricardian interpretation for this outcome exists as well, but the authors regard this as less plausible for the following reason. For a non-Ricardian regime to hold in this case, the decrease in the debt ratio has to result from a decrease in the expected present value of future balances. This means that there has to be a negative correlation between the current balance and future balances. The increase in the current balance has to trigger a decrease in future balances which in turn lowers the debt ratio in case of a non-Ricardian regime. Since the authors do not find this negative correlation, they conclude that a Ricardian regime is more plausible for their data.

Semmler and Zhang (2004) perform a VAR analysis similar to CCD for France during the period 1967 until 1998 and for Germany for the period 1970 until 1998. In contrast to $\mathrm{CCD}$, Semmler and Zhang exclude the monetary base; their endogenous variables are primary balance and government debt, both proportional to GDP. Excluding the monetary base excludes the possibility of fiscal price determination occurring as a result of monetary phenomena such as seigniorage (Sargent and Wallace 1981). The exclusion of the monetary base fully disentangles monetary and fiscal price determination, which is also stressed by Creel and Le Bihan (2006). The impulse responses of Semmler and Zhang also indicate that the debt ratio decreases for several periods after an increase in the balance. As explained above, this can occur in both a Ricardian and a non-Ricardian regime. Contrary to CCD, Semmler and Zhang analyse a debt shock in order to differentiate between a Ricardian and a non-Ricardian regime in case debt responds negatively to a surplus shock. The impulse responses indicate that the balance decreases after a positive shock to the debt ratio. In a Ricardian regime, a positive response of the balance is expected after a positive shock to debt. Since the authors do not find this positive response, they conclude that a non-Ricardian regime is more plausible for France and Germany. Nevertheless, in a non-Ricardian regime no predictions can be made about the response of the balance after a debt shock. Therefore, we apply the methodology of CCD and examine the correlation structure of balances in case we find a negative response of debt after a positive shock to the balance. However, we follow Semmler and Zhang in excluding the monetary base.

Finally, another, more recent literature can be mentioned, which analyses fiscalmonetary interactions in a more technical way. Muscatelli et al. (2002) and Semmler and Zhang (2004) use a state-space model with Markov-switching to analyse the interactions between monetary and fiscal policies in the euro area. This model allows for multiple structural breaks in the time series. We do not opt for such an approach as we already know the structural break points (i.e. the introduction of the ECC and the start of the GFC). 


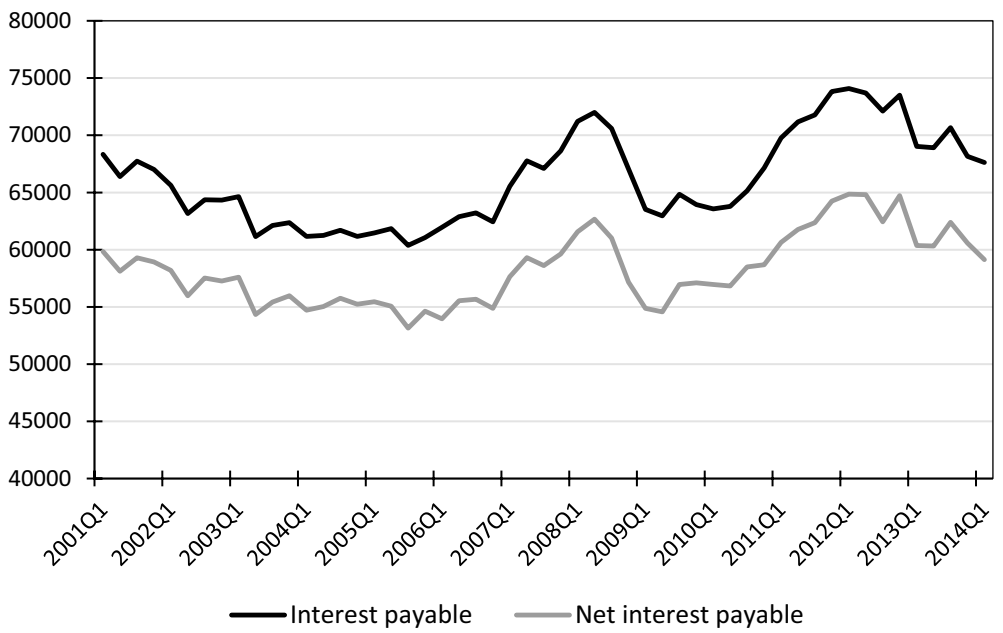

Fig. 2 Interest payable versus net interest payable, i.e. interest payable minus interest receivable, for the euro area aggregate

\section{Data}

To analyse the plausibility of Ricardian versus non-Ricardian fiscal regimes at the euro area level, we use the Area Wide Model (AWM) fiscal database of the ECB, which is compiled by Paredes et al. (2014). The dataset includes seasonally adjusted data on the levels of general government revenues, expenditures, and debt for the euro area-18 aggregate. ${ }^{1}$ The time period that is available is $1980 \mathrm{q} 2-2013 \mathrm{q} 4$.

To construct the primary balance variable, net interest payable should be added to the total government balance. However, the AWM fiscal database only includes data on interest payable and not on interest receivable. Data on interest receivable and interest payable can be obtained from the Eurostat Government Finance Statistics database, albeit for a shorter time span. The seasonally adjusted series (using Census X13) are exhibited in Fig. 2. Net interest payable and interest payable follow roughly the same pattern for the euro area-18. In addition, the fraction of interest receivable in the net interest calculation is fairly small. Therefore, interest receivable is considered to be zero and the interest payable from the AWM database is interpreted as being net interest payable. Thus, primary balances are calculated as net borrowing or lending plus interest payable.

Nominal GDP is also obtained from the AWM database, that is, from the nonfiscal counterpart compiled by the ECB. It is inferred from real GDP and the GDP deflator, since the AWM database does not give the nominal GDP as such.

From the data on the primary balance, government debt and nominal GDP, we calculate the balance and debt ratios. Figure 3 shows the time series for the euro area. Descriptive statistics for the two variables are given in Table 1. Two

\footnotetext{
1 The euro area-18 consists of: Austria, Belgium, Cyprus, Estonia, Finland, France, Germany, Greece, Ireland, Italy, Latvia, Luxembourg, Malta, The Netherlands, Portugal, Slovakia, Slovenia, and Spain.
} 


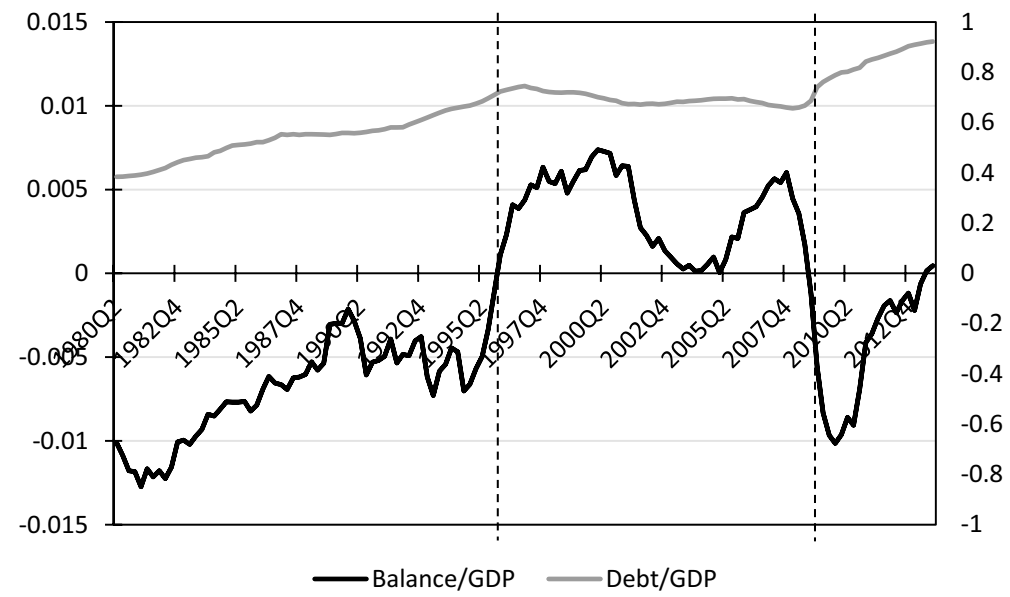

Fig. 3 Primary government balance (left y-axis) and debt (right y-axis), both proportional to nominal GDP, for the euro area aggregate. Note: the first vertical line indicates the break occurring at the introduction of the ECC. The second vertical line indicates the break occurring at the start of the GFC

Table 1 Descriptive statistics of balance-to-GDP ratio and debt-to-GDP ratio for the euro area aggregate (sample period: 1980q2-2013q4)

\begin{tabular}{lll}
\hline & Balance/GDP & Debt/GDP \\
\hline Sample mean & -0.002 & 0.644 \\
Standard deviation & 0.006 & 0.129 \\
Minimum & -0.013 & 0.384 \\
Maximum & 0.007 & 0.922 \\
Observations & 135 & 135 \\
\hline
\end{tabular}

significant structural breaks seem to be present when examining Fig. 3. The first one occurs around the implementation of the ECC fiscal requirements in the third quarter of 1997 and is depicted by the first vertical line. The ECC enforced rules on the fiscal policies of euro area countries which led to a sharp increase in primary balances. The second structural break occurs around 2008q 3 and is depicted by the second vertical line. It corresponds to the start of the GFC, which caused primary deficits and government debts to increase sharply.

A Chow (1960) structural break test reveals that structural breaks indeed occur in $1997 \mathrm{q} 3$ and 2008q3. The $F$-statistics in Table 2 show that for both series the structural breaks are statistically significant at a $1 \%$ significance level. Standard Augmented Dickey-Fuller unit root tests (without structural breaks) suggest that both series are stationary. ${ }^{2}$ Hence we estimate our VAR in levels.

\footnotetext{
${ }^{2}$ We also tried the Lagrange Multiplier unit root test with two structural breaks of Lee and Strazicich (2003). This test did not give satisfactory results, when allowing for changes in the intercept and the trend slope.
} 
Table $2 F$-statistics of a Chow test including both an intercept dummy and a slope dummy

\begin{tabular}{lrc}
\hline & \multicolumn{1}{c}{$D_{E C C}$} & $D_{G F C}$ \\
\hline Balance/GDP & 90.27 & 177.00 \\
Debt/GDP & 229.49 & 233.54 \\
\hline
\end{tabular}

$D_{E C C}$ equals 0 for periods before $1997 \mathrm{q} 3$ and 1 for periods after 1997q3. $D_{G F C}$ equals 0 for periods before $2008 \mathrm{q} 3$ and 1 for periods after $2008 \mathrm{q} 3$. The critical $F$ value for a $1 \%$ significance level in our sample is $F(2,131)=4.77$

Based on the results of the Chow break tests, two dummy variables are constructed, one for the introduction of the ECC $\left(D_{E C C}\right)$ and one for the recent financial crisis $\left(D_{G F C}\right) . D_{E C C}$ is constructed to equal 0 for periods before $1997 \mathrm{q} 3$ and to equal 1 for periods after $1997 \mathrm{q} 3 . D_{G F C}$ is constructed to equal 0 for periods before $2008 \mathrm{q} 3$ and to equal 1 for periods after $2008 \mathrm{q} 3$.

\section{Method}

We test the empirical plausibility of Ricardian and non-Ricardian regimes using the approach of CCD. Specifically, we estimate a VAR model and analyze the dynamics between government debt and the primary balance. This section first explains how to estimate a VAR model when there are breaks in the data and then discusses the analytical framework we use to determine whether a Ricardian or a non-Ricardian regime is more plausible.

\subsection{VAR modelling with breaks}

The estimated VAR model includes two variables: the government's primary balance in period $t, s_{t}$, and the government debt at the beginning of period $t, w_{t}$. Both are proportional to GDP. As has been shown in Sect. 3, two breaks are present during our sample period, the first due to the introduction of the ECC and the second after the start of the Global Financial Crisis (GFC) in 2008. We treat the breaks as known and use time dummies to address them. We estimate a VAR model including two dummy interaction terms. Splitting the sample in three sub-periods and estimation of three VARs is no option because of the resulting loss of observations. Therefore, dummy interaction terms are introduced and the model is estimated for the whole sample period. The first dummy interaction term accounts for the implementation of the Euro Convergence Criteria $\left(D_{E C C}\right)$ and the second accounts for the start of the GFC $\left(D_{G F C}\right)$. The reduced-form model, including $p$ lags, looks as follows:

$$
\begin{aligned}
s_{t}= & \alpha_{s}+\beta_{s} D_{E C C}+\gamma_{s} D_{G F C}+\delta_{s s}(L) s_{t-1}+\delta_{s w}(L) w_{t-1}+\eta_{s s}(L) s_{t-1} D_{E C C}+\eta_{s w}(L) w_{t-1} D_{E C C} \\
& +\theta_{s s}(L) s_{t-1} D_{G F C}+\theta_{s w}(L) w_{t-1} D_{G F C}+e_{t}^{s} \\
w_{t}= & \alpha_{w}+\beta_{w} D_{E C C}+\gamma_{s} D_{G F C}+\delta_{w s}(L) s_{t-1}+\delta_{w w}(L) w_{t-1}+\eta_{w s}(L) s_{t-1} D_{E C C} \\
& +\eta_{w w}(L) w_{t-1} D_{E C C}+\theta_{w s}(L) s_{t-1} D_{G F C}+\theta_{w w}(L) w_{t-1} D_{G F C}+e_{t}^{w}
\end{aligned}
$$


where $\delta_{i j}(L)=\delta_{1 . i j}+\delta_{2 . i j} L+\cdots+\delta_{p . i j} L^{p-1}$ for $i, j=s, w$, and $\eta_{i j}(L)$ and $\theta_{i j}(L)$ are similar polynomials. In short-hand matrix notation:

$$
Z_{t}=\alpha+\beta D_{E C C}+\gamma D_{G F C}+\delta(L) Z_{t-1}+\eta(L) Z_{t-1} D_{E C C}+\theta(L) Z_{t-1} D_{G F C}+e_{t} .
$$

Hence, each endogenous variable is explained by a constant, a constant interacted with both dummy variables, lagged values for both endogenous variables, lagged values interacted with both dummy variables, and an error term. The error term is assumed to be serially and mutually uncorrelated. Equation (5) can be estimated by means of Ordinary Least Squares (OLS), since both equations contain the same set of lagged variables. The inclusion of the dummy variables as exogenous variables enables us to determine whether the constant in the regression equations changes after the breaks. Moreover, the dummy interaction terms are added as endogenous variables in order to determine whether the slopes of the regression equations change after the occurrence of the breaks.

After estimating the above VAR model, three VAR models are created from the estimated coefficients. Each of the three separate models represents a different period.

The IRFs are calculated by imposing a recursive ordering as in Sims (1980). The primary balance is ordered before debt. In other words, the balance affects debt contemporaneously. To obtain standard errors for the estimated coefficients and confidence intervals for the IRFs of the VAR model including the dummy interaction terms, we cannot apply the standard methodology based on critical values and asymptotic distribution. Instead we use the bootstrap methodology of Runkle (2002). This methodology is a parametric bootstrap method that is suitable for time series data since it preserves the temporal dependence of the data in generating bootstrap samples. ${ }^{3}$ The method proceeds as follows:

1. Estimate the reduced-form model in Eq. (5) using OLS. This gives the estimates: $\hat{\alpha}, \hat{\beta}, \hat{\gamma} \widehat{\delta(L)}, \widehat{\eta(L)}, \widehat{\theta(L)}$ and $\widehat{e_{t}}$.

2. Using the estimated coefficients and residuals of the fitted model, estimate the linear predictions for the endogenous variables. Using the reducedform model specified above, the linear predictions are calculated as: $\hat{Z}_{t}=\hat{\alpha}+\hat{\beta} D_{E C C}+\hat{\gamma} D_{G F C}+\widehat{\delta(L)} Z_{t-1}+\widehat{\eta(L)} Z_{t-1} D_{E C C}+\widehat{\theta(L)} Z_{t-1} D_{G F C} \quad$ f o r $t=(1+p), \ldots, N$, where $p$ is the number of lags and $N$ is the total number of observations.

3. Using the linear predictions $\hat{Z}_{t}$, create bootstrapped time-series, $Z_{t}^{*}$, for $t=(1+p), \ldots, N$, as follows: $Z_{t}^{*}=\hat{Z}_{t}+e_{t}^{*}$, where $e_{t}^{*}$ is a random draw from the empirical distribution of the residuals.

4. Estimate the reduced-form VAR as in Eq. (5) using the bootstrapped time-series in $Z_{t}^{*}$ as dependent variables.

\footnotetext{
3 The original bootstrap methodology of Efron (1982) cannot be used as this assumes that all observations in the sample are assumed to be independently distributed. This is too restrictive for time series data.
} 
5. Compute impulse response functions for both endogenous variables using the coefficients given by the estimated VAR of the bootstrapped series of step 4 .

6. Repeat steps 3-5 for a fixed number of times. The number of iterations we used is 1000 .

Confidence bands are obtained by taking the 5th and the 95th percentile impulse responses.

\subsection{Analytical framework}

To investigate whether a Ricardian regime or a non-Ricardian regime is more plausible, we analyse the effects of a one-period increase in $s_{t}$. Impulse Response Functions (IRFs) show how the balance and debt ratio respond in the current period and future periods. Figure 4 summarizes our analytical framework, which is adopted from CCD.

In a Ricardian regime, a negative response of $w_{t+1}$ should always follow a positive shock in $s_{t}$ since in this case the higher balance is used to pay off government debt in the next period. A non-Ricardian regime is slightly more difficult to identify. The response of the debt ratio in a non-Ricardian regime depends on the possible correlation between the current balance and future balances. First, consider the case of a nonRicardian regime and no correlation between the current balance and future balances. In such a case, an innovation in $s_{t}$ will lead to a zero change in $w_{t+1}$ for the following reasons. In period $t$, the increase in $s_{t}$ leads to a one-by-one increase in $w_{t}$ through a decrease in the price level as a result of one of the mechanisms explained in Sect. 2. In the next period, the increase in $s_{t}$ pays off debt by the same amount. Therefore, $w_{t+1}$ is unaffected by an increase in $s_{t}$.

Next, consider the case of a non-Ricardian regime and positive correlation between the current balance and future balances. In this case, a positive response of $w_{t+1}$ will follow after a positive shock in $s_{t}$. The innovation in $s_{t}$ leads to a higher expected present value of future balances as a result of the positive correlation. Even though the shock in $s_{t}$ pays off part of the debt in period $w_{t+1}$, the increased present value of future

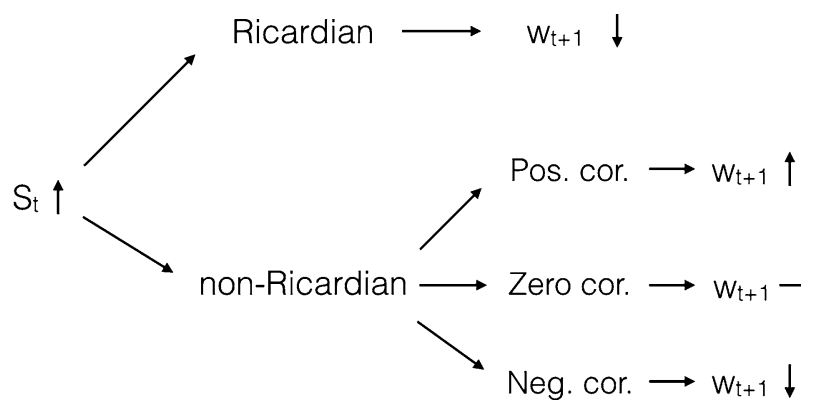

Fig. 4 Analytical framework Ricardian versus non-Ricardian regime. Note: After an (unexpected) positive shock to $s_{t}$, a decrease in $\mathrm{w}_{t}$ is expected in a Ricardian regime. In a non-Ricardian regime, the response of $\mathrm{w}_{t}$ depends on the autocorrelation structure of government balances. In case of zero autocorrelation between current and future balances, no response of $\mathrm{w}_{t}$ is expected in the period after the shock. In case of positive (negative) autocorrelation, a positive (negative) response of $\mathrm{w}_{t}$ is expected 
balances leads to a decrease in the price level. Consequently, $w_{t}$ and $w_{t+1}$ are expected to respond positively to an increase in $s_{t}$.

Last, consider the case of a non-Ricardian regime and negative correlation between the current balance and future balances. In such a case, a negative response of $w_{t+1}$ will occur after a positive shock in $s_{t}$ since the shock leads to a lower expected present value of future balances. The decrease in the expected present value of future balances will lower $w_{t}$ through an immediate increase in the price level. In addition, the higher balance pays off part of the debt which leads to a lower $w_{t+1}$ as well. Thus, an observed negative response of $w_{t+1}$ may be evidence in favour of a Ricardian regime or a non-Ricardian regime depending on the correlation between the current balance and future balances.

In order to identify whether a Ricardian or a non-Ricardian regime is more plausible in case of a negative response of $w_{t+1}$, we will follow CCD and analyse autocorrelation coefficients between the current balance and future balances. In a non-Ricardian regime, a negative response of $w_{t+1}$ can only occur if there is a negative correlation between the current balance and future balances. On the other hand, a negative response of $w_{t+1}$ together with a positive correlation between the current balance and future balances is interpreted as evidence in favour of a Ricardian regime.

Thus, if a positive shock to the balance is followed by a negative response of debt, and the autocorrelation of balances is positive (negative), the regime is Ricardian (non-Ricardian). If a positive shock to the balance is followed by a positive response of debt, and autocorrelation of balances is positive, the regime is non-Ricardian. If a positive shock to the balance is followed by a zero response of debt, and the autocorrelation of balances is zero, the regime is also non-Ricardian.

\section{Results}

Estimation of the VAR model described in Sect. 4.1 for the euro area aggregate gives the estimated parameters presented in Table 3. Two lags are included in the VAR as suggested by several lag length criteria. ${ }^{4}$ An eigenvalue stability test shows that all eigenvalues lie within the unit circle which indicates that the estimated VAR is stable.

The estimated coefficients are obtained by first estimating a VAR model including the dummy interaction terms as endogenous variables for the whole sample period. Estimation by OLS gives us estimates for the constant terms, for the parameters of the endogenous variables and for the parameters of the dummy interaction terms.

The inclusion of the two dummy interaction terms allows us to distinguish three periods. The period for which $D_{E C C}=D_{G F C}=0$ corresponds to the period before the implementation of the ECC and before the start of the GFC, and it will be referred to as the pre-ECC period. The period for which $D_{E C C}=1$ and $D_{G F C}=0$ corresponds to the period after the implementation of the ECC but before the start of the GFC. It will be referred to as the post-ECC period. The period for which $D_{E C C}=$

\footnotetext{
4 To determine the appropriate lag length, the following information criteria are analysed: the likelihood ratio (LR), the final prediction error (FPE), Akaike's information criterion (AIC), the Hannan-Quinn information criterion (HQIC), and Schwarz's Bayesian information criterion (SBIC). All information criteria suggest that including two lags is optimal for our VAR estimation.
} 


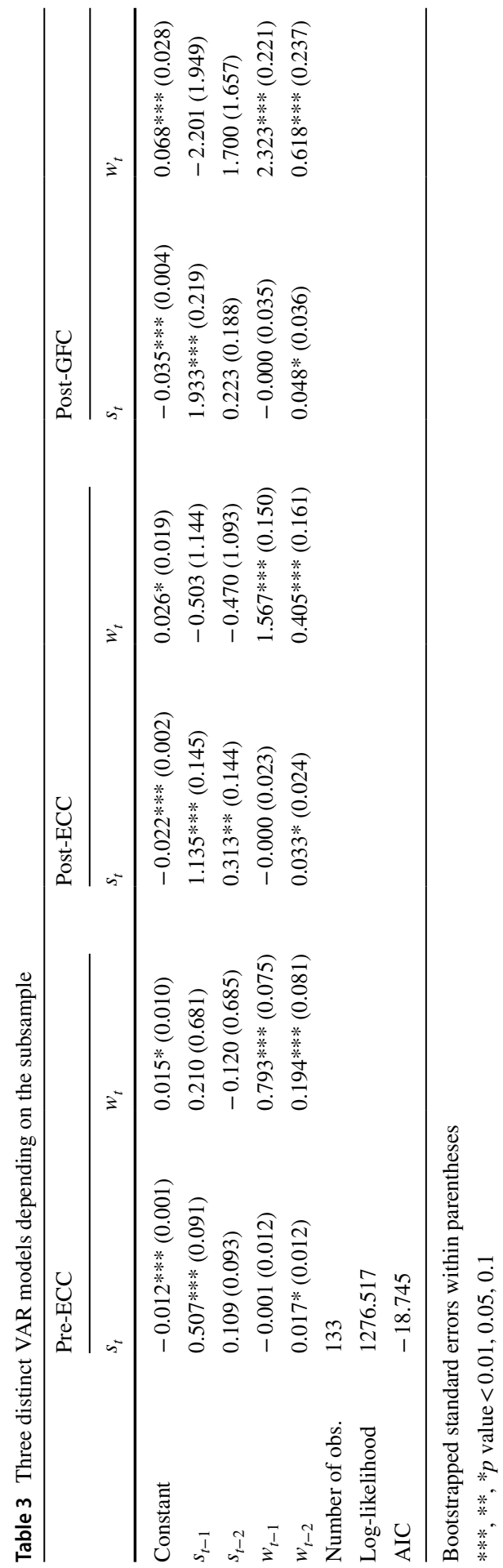


$D_{G F C}=1$ corresponds to the period after the implementation of the ECC and after the start of the GFC, and it will be referred to as the post-GFC period. The three distinct VAR models are constructed by adding the coefficients of the endogenous variables to the estimated coefficients of the respective dummy interaction terms, as explained in Sect. 4.1.

Comparing the estimated VAR models for the three periods shows that the signs of the estimated coefficients are generally the same while their magnitudes may differ across the three periods. A difference exists between the estimated coefficients of the debt equations which may lead to differences in the IRFs. As the estimated response of debt deserves most interest in our analytical framework, these differences in the estimated coefficients suggest that contrasting conclusions may arise across the three periods.

The IRFs are calculated for the three distinct VAR models. Different conclusions are drawn for each period as is discussed below. In constructing the IRFs, the primary balance is ordered first. We examine the robustness of the results by using different specifications of the VAR models. ${ }^{5}$ The results are robust to the exclusion of the constant term, the inclusion of a time trend and the inclusion of 1 lag instead of 2 lags. Furthermore, the VARs are also estimated by specifying both variables in first differences. Alternative IRFs are calculated by using the reverse ordering of the variables. For the latter two specifications the results are qualitatively the same; however, the confidence intervals are wider.

\subsection{Pre-ECC}

The period of our first VAR model corresponds to the pre-ECC period. During this period government balances have generally increased in the euro area in order to comply with the fiscal requirements of the ECC. This is also shown in Fig. 3 where balances increase sharply around 1997q3, the quarter in which the fiscal requirements were introduced. At the same time, the debt ratio decreases. As a result a Ricardian regime is expected to be more applicable for this period.

Figure 5 shows the IRFs of both variables after a positive shock to the balance in the pre-ECC period. As can be seen, the estimated response of debt does not significantly differ from zero. Referring to our analytical framework, presented in Fig. 4, a zero response of debt after a positive shock to the balance can be seen as evidence in favour of a non-Ricardian regime. However, this is only the case if correlation between the current balance and future balances is also zero.

Therefore, to determine whether a Ricardian or a non-Ricardian regime is more plausible given the negative response of debt, an analysis of the correlation structure of balances is needed. Autocorrelation coefficients of balances for the three distinct periods are given in Table 4. For the pre-ECC period, autocorrelation coefficients are positive and significant for at least 15 periods. Therefore, our results are not considered to be favourable for either of the two regimes.

\footnotetext{
${ }^{5}$ For reasons of space, the results of the robustness are not reported, but are available from the authors.
} 
Fig. 5 Impulse response functions after a positive structural shock to the balance (pre-ECC period) (a) Debt/GDP

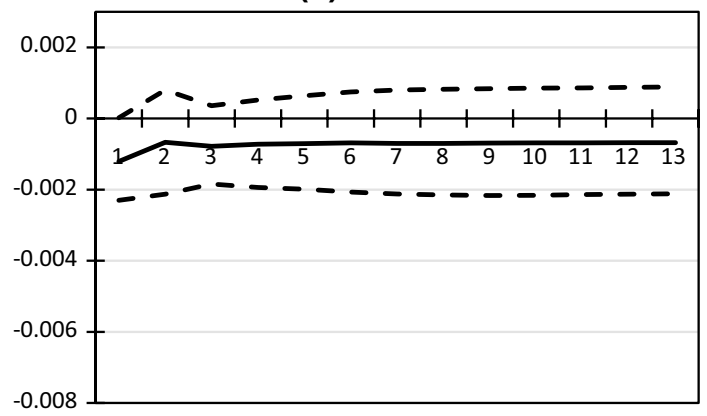

(b) Balance/GDP

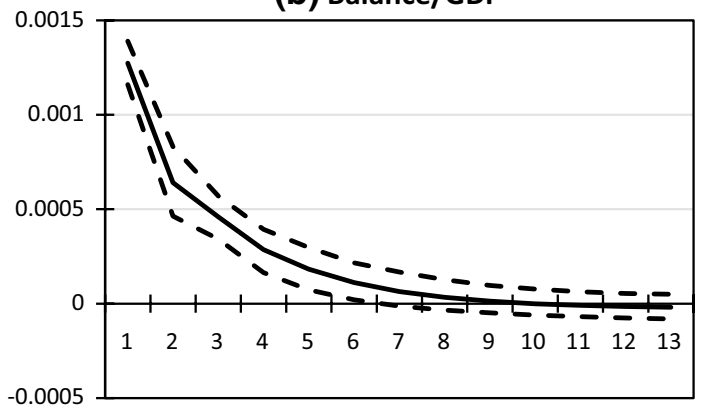

\subsection{Post-ECC until GFC}

Figure 6 shows the IRFs of both variables after a positive shock to the balance in the post-ECC period until the GFC. The response of debt is negative and significant after 2 periods. As shown in Fig. 4, a negative response of debt can occur in both a Ricardian and a non-Ricardian regime. Therefore, in order to examine which fiscal regime is more plausible, correlation coefficients between the current balance and future balances need to be analysed.

Autocorrelation coefficients of balances for the post-ECC period are given in Table 4. For this period, autocorrelation coefficients are positive for the first nine lags but after the tenth lag autocorrelation coefficients turn negative, meaning that a positive balance in the current period is negatively correlated to the balance ten quarters later. As explained above, a non-Ricardian regime is plausible when the response of debt is negative and correlation between the current balance and future balances is negative.

However, we still consider a Ricardian regime more plausible. For later periods, the autocorrelation coefficients become smaller in absolute value. As a result, the change in present value of balances due to the positive shock to the balance is still expected to be positive. If the present value change in balance is positive, in a nonRicardian regime, a positive response of debt is expected, which we do not find. 
Table 4 Autocorrelations of balances for the three consecutive periods

\begin{tabular}{|c|c|c|c|c|c|c|c|c|c|}
\hline \multirow[t]{2}{*}{ Lag } & \multicolumn{3}{|c|}{ Pre-ECC } & \multicolumn{3}{|l|}{ Post-ECC } & \multicolumn{3}{|c|}{ Post-GFC } \\
\hline & $\mathrm{AC}$ & Q & Prob $>$ Q & $\mathrm{AC}$ & Q & Prob $>$ Q & $\mathrm{AC}$ & Q & Prob $>$ Q \\
\hline 1 & 0.9174 & 61.48 & 0.000 & 0.9402 & 41.61 & 0.000 & 0.8126 & 16.602 & 0.000 \\
\hline 2 & 0.8172 & 110.98 & 0.000 & 0.8641 & 77.596 & 0.000 & 0.5665 & 25.073 & 0.000 \\
\hline 3 & 0.7177 & 149.72 & 0.000 & 0.7847 & 107.99 & 0.000 & 0.3557 & 28.59 & 0.000 \\
\hline 4 & 0.6172 & 178.81 & 0.000 & 0.6708 & 130.76 & 0.000 & 0.1774 & 29.513 & 0.000 \\
\hline 5 & 0.5132 & 199.24 & 0.000 & 0.5589 & 146.97 & 0.000 & 0.0099 & 29.516 & 0.000 \\
\hline 6 & 0.4199 & 213.12 & 0.000 & 0.4379 & 157.19 & 0.000 & -0.1104 & 29.918 & 0.000 \\
\hline 7 & 0.3313 & 221.9 & 0.000 & 0.3026 & 162.2 & 0.000 & -0.2000 & 31.327 & 0.001 \\
\hline 8 & 0.2645 & 227.59 & 0.000 & 0.1696 & 163.81 & 0.000 & -0.2825 & 34.337 & 0.000 \\
\hline 9 & 0.2201 & 231.59 & 0.000 & 0.0436 & 163.92 & 0.000 & -0.2758 & 37.426 & 0.000 \\
\hline 10 & 0.1949 & 234.78 & 0.000 & -0.0743 & 164.25 & 0.000 & -0.2622 & 40.451 & 0.000 \\
\hline 11 & 0.1746 & 237.38 & 0.000 & -0.1781 & 166.2 & 0.000 & -0.2860 & 44.378 & 0.000 \\
\hline 12 & 0.1615 & 239.65 & 0.000 & -0.2733 & 170.92 & 0.000 & -0.2945 & 48.956 & 0.000 \\
\hline 13 & 0.1554 & 241.78 & 0.000 & -0.3530 & 179.06 & 0.000 & -0.2747 & 53.382 & 0.000 \\
\hline 14 & 0.1341 & 243.4 & 0.000 & -0.4206 & 190.99 & 0.000 & -0.2424 & 57.261 & 0.000 \\
\hline 15 & 0.1133 & 244.58 & 0.000 & -0.4955 & 208.13 & 0.000 & -0.2200 & 60.913 & 0.000 \\
\hline
\end{tabular}

AC refers to the autocorrelation coefficient.. Q refers to a Portmanteau (Q) test statistic that tests against the null hypothesis of white noise

Fig. 6 Impulse response functions after a positive structural shock to the balance (post-ECC period) (a) Debt/GDP

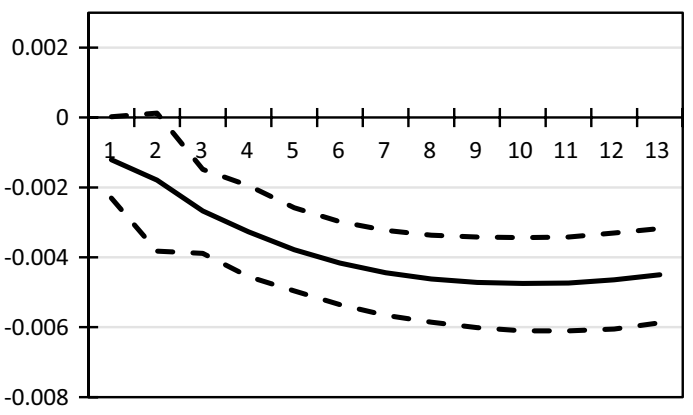

(b) Balance/GDP

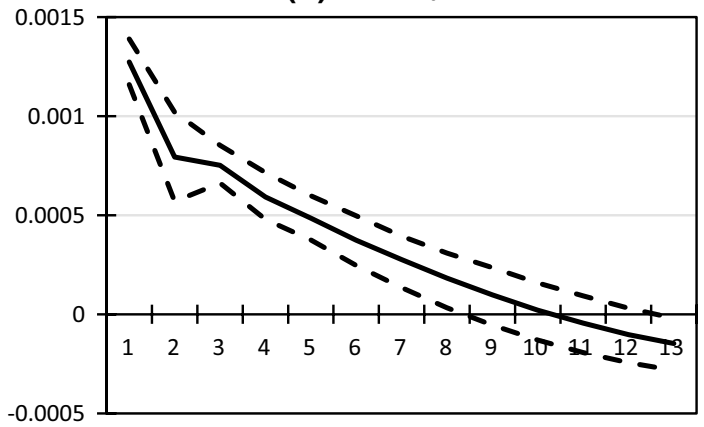


Therefore, we conclude that a Ricardian regime is more plausible for the post-ECC period.

In addition, the IRFs show that according to our estimated model, a positive response of the balance is expected after a positive shock to the balance. This can be seen as additional evidence for the positive autocorrelation of balances and as additional evidence in favour of a Ricardian regime.

\subsection{Post-GFC}

At the start of the GFC around the third quarter of 2008, deficits increased sharply in the euro area. This structural break is clearly present in Fig. 3 for both variables. During this period government balances (or rather deficits) were not necessarily determined by the debt ratio but rather by large shocks caused by the financial crisis. As a result, a non-Ricardian regime is considered more likely for this period.

Figure 7 shows the IRFs of both variables for the post-GFC period. Again, after a positive shock to the balance, the immediate response of debt is negative. However, the response quickly turns insignificant. As shown in Fig. 4, a negative response of debt can occur in both a Ricardian and a non-Ricardian regime. The correlation

Fig. 7 Impulse response functions after a positive structural shock to the balance (post-GFC period) (a) Debt/GDP

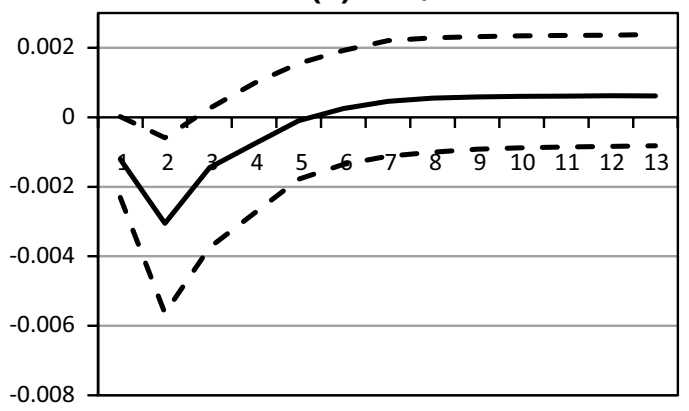

(b) Balance/GDP

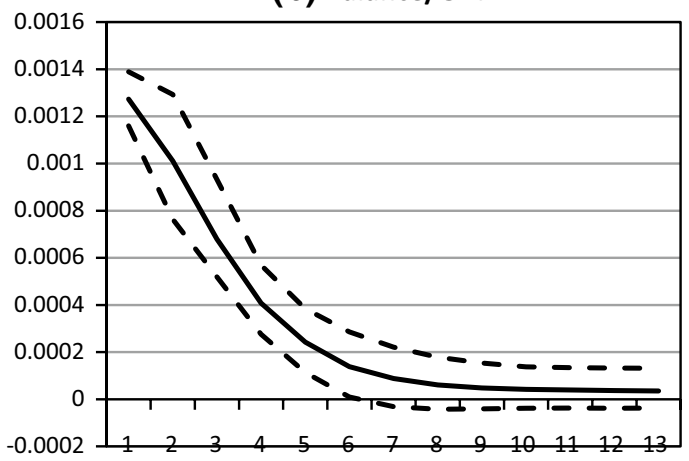


structure of balances needs to be analysed, in order to determine which regime is more plausible.

Autocorrelation coefficients of balances for the post-GFC period are given in Table 4 and are positive until 5 lags. Thereafter, the autocorrelation coefficients turn negative. Since most coefficients are negative, a decrease in the expected present value of balances after a positive shock to the balance is more likely for this period. Consequently, given our analytical framework in Fig. 4, the evidence points in the direction of a non-Ricardian regime in the post-GFC period.

However, the fact that only a short period is available to calculate the autocorrelations for the last period makes it hard to derive firm conclusions. Autocorrelation coefficients are given for 15 lags and for the last lags available, autocorrelation coefficients tend to become lower in absolute value. Consequently, whether a decrease in the present value of balances is expected depends on subjective judgement.

Moreover, the estimated response of the balance after a positive shock to the balance in Fig. 7 is positive and significant up to 6 periods. Therefore, the estimated response of the balance presents contrasting evidence for the negative correlation structure of balances found in Table 4. As a result, we are not able to conclude with certainty whether a Ricardian or a non-Ricardian regime is more plausible for the post-GFC period. Nevertheless, the initial negative and significant response of debt in Fig. 7 combined with the negative autocorrelation coefficients in Table 4 present some evidence in favour of a non-Ricardian regime.

\section{Conclusion}

To investigate whether a Ricardian or a non-Ricardian regime is more plausible for the euro area, we estimate a VAR model, following Canzoneri et al. (2001). The model includes the variables primary government balance and government debt. We extend the methodology used by CCD by including two dummy interaction terms in our VAR model that account for the two structural breaks that are present in the period to be analysed. The first dummy interaction term accounts for the introduction of the ECC and the second dummy interaction term accounts for the start of the GFC.

The impulse response functions for the pre-ECC period do not point towards either of the two regimes. For this period, the response of debt after a positive shock to the balance is not significantly different from zero. This can be evidence in favour of a non-Ricardian regime if the current balance and future balances are not correlated. Since we do not find this zero correlation, our results are not considered to be favourable for either of the two regimes.

For the period between the introduction of the ECC and the start of the GFC we find a negative response of debt after a positive shock to the balance. This negative response can be evidence in favour of both a Ricardian and a non-Ricardian regime. However, in a non-Ricardian regime, the negative response can only be explained if there exists a negative correlation between the current balance and future balances. Since evidence for this cannot be found, a Ricardian regime is more plausible for the post-ECC period. Thus, during this episode the EMU worked as it should to 
promote fiscal solvency and monetary policy is the nominal anchor in determining the price level.

For the post-GFC period, the debt ratio again responds negatively to an increase in the balance. However, in this case we do find some evidence for a negative correlation between the current balance and future balances. Whether this negative correlation leads to a decrease in the expected present value of balances and, thus, presents evidence in favour of a non-Ricardian regime, depends on subjective judgement. Moreover, the IRFs of our estimated model show a positive response of the balance after a positive shock to the balance. Therefore, even though some evidence exists in favour of a non-Ricardian regime in the period after the start of the GFC, it is not conclusive. Yet, the existence of a non-Ricardian regime has important implications for the effectiveness of monetary policy as fiscal policy becomes the nominal anchor in stabilizing the euro area price level.

In summary, our modeling results only give conclusive and unambiguous evidence of a Ricardian fiscal policy for the sub-period starting with the introduction of the euro convergence criteria (ECC) and ending with the global financial crisis (GFC). This outcome is plausible, as during the early years of EMU, countries did make strong efforts to fulfill the ECC needed for membership of the currency union. The ECC prompted participating countries to aim at fiscal solvency by reducing deficits and reaching sustainable debt levels. Thus, the EMU during this episode worked as it should to promote fiscal solvency. Unfortunately, the GFC strongly shocked the banking sector in most euro area countries which forced governments to bail out large and systemically important banks, and led to a severe recession. The GFC led to higher deficits and debt. Consequently, for the period since the GFC, we find no conclusive evidence of Ricardian fiscal policy.

Open Access This article is distributed under the terms of the Creative Commons Attribution 4.0 International License (http://creativecommons.org/licenses/by/4.0/), which permits unrestricted use, distribution, and reproduction in any medium, provided you give appropriate credit to the original author(s) and the source, provide a link to the Creative Commons license, and indicate if changes were made.

\section{References}

Barro RJ (1979) On the determination of the public debt. J Polit Econ 87:940-971

Bohn H (1995) The sustainability of budget deficits in a stochastic economy. J Money Credit Bank 27:257-271

Bohn H (1998) The behavior of U.S. public debt and deficits. Quart J Econ 113:949-963

Bohn H (2005) The sustainability of fiscal policy in the United States. CESifo Working Paper No. 1446

Canzoneri MB, Cumby RE, Diba BT (2001) Is the price level determined by the needs of fiscal solvency? Am Econ Rev 91:1221-1238

Chow GC (1960) Tests of equality between sets of coefficients in two linear regressions. Econometrica 28:591-605

Creel J, Le Bihan H (2006) Using structural balance data to test the fiscal theory of the price level: some international evidence. J Macroecon 28:338-360

Efron B (1982) The jackknife, the bootstrap and other resampling plans. Society for Industrial and Applied Mathematics, Philadelphia

Greiner A, Köller U, Semmler W (2007) Debt sustainability in the European Monetary Union: theory and empirical evidence for selected countries. Oxf Econ Pap 59:194-218 
Lee J, Strazicich MC (2003) Minimum Lagrange Multiplier unit root test with two structural breaks. Rev Econ Stat 85:1082-1089

Leeper EM (1991) Equilibria under active and passive monetary and fiscal policies. J Monet Econ 27:129-147

Muscatelli VA, Tirelli P, Trecroci C (2002) Monetary and fiscal policy interactions over the cycle: some empirical evidence. CES-Ifo Working Paper No. 817

Paredes J, Pedregal DJ, Perez JJ (2014) Fiscal policy analysis in the euro area: expanding the toolkit. J Policy Model 36:800-823

Runkle DE (2002) Vector autoregressions and reality. J Bus Econ Stat 20:128-133

Sargent TJ, Wallace N (1981) Some unpleasant monetarist arithmetic. Fed Reserve Bank Minneap Q Rev 5:1-17

Schuknecht L, Moutot P, Rother P, Stark J (2011) The stability and growth pact: crisis and reform. ECB Occasional Paper 129

Semmler W, Zhang W (2004) Monetary and fiscal policy interactions in the euro area. Empirica 31:205-227

Sims CA (1980) Macroeconomics and reality. Econometrica 48:1-48

Sims CA (1994) A simple model for study of the determinacy of the price level and the interaction of monetary and fiscal policy. Econ Theor 4:381-399

Sims CA (2016) Fiscal policy, monetary policy and central bank independence. Address at the Economic Policy Symposium hosted by the Federal Reserve Bank of Kansas City, Jackson Hole

Woodford M (1994) Monetary policy and price level determinacy in a cash-in-advance economy. Econ Theor 4:345-380

Woodford M (1995) Price-level determinacy without control of a monetary aggregate. In: CarnegieRochester conference series on public policy, vol 43, pp. 1-46

Publisher's Note Springer Nature remains neutral with regard to jurisdictional claims in published maps and institutional affiliations. 